\title{
EFFECTS OF COOLING MEDIA ON THE MECHANICAL PROPERTIES AND MICROSTRUCTURE OF SAND AND DIE CASTING ALUMINIUM ALLOYS
}

\author{
B.O. Adewuyi and J.A. Omotoyinbo \\ Department of Metallurgical and Materials Engineering, \\ Federal University of Technology, Akure.
}

\begin{abstract}
Die and sand castings are versatile processes capable of being used in mass production of alloys having properties unobtainable by other manufacturing method. In this research, efforts were made to study the effects of cooling media on Aluminium alloy cast. Aluminium scrap ( $\mathrm{Al}-\mathrm{Mg}-\mathrm{Si}$,) were charged into crucible furnace from which as-cast aluminium samples for the experimental work were obtained. The specimens were subjected to hardness test, tensile test and metallographic examination. The results show that samples obtained from air cooled dies had the best mechanical properties and those produce by sand casting had comparable hardness values but lower tensile properties. Other results show that the hardness of cast alloys can be varied by changing the cooling media.
\end{abstract}

Keywords: Die casting, cooling media, aluminium

\section{INTRODUCTION}

Behaviors of engineering materials under service stresses and environments are the most riding considerations in material selections. The effect of defective castings on the structure and mechanical properties cannot be overemphasized as it accounts for the enormous high losses incurred by foundry industries. Casting defects may be due to faulty casting design or the method of casting. Under normal working conditions some defects in castings may be inherent and their significance can only be established in relation to the functions of the casting. Defects in castings can affect the mechanical properties and surface conditions of castings, hence strength and appearance are considered to be very important. Casting defects in cast aluminium alloys may include: blow holes, cold shuts, hot tear, slag inclusions etc. In this work, effort is made to consider some of the major ways of improving the mechanical properties of cast aluminium alloys by minimizing the casting defects by subjecting the castings to different cooling media. Such media is expected to modify the microstructure and enhance the hardness and tensile strength of the cast aluminium alloys, Adewuyi (2001). 
Casting processes are generally classified by mould materials, mould processes, and method of feeding the mould with the molten metal. Two major categories of casting are expendable moulds and permanent mould castings. Sand casting is the traditional method of expendable mould casting. Typical parts made by sand casting are machine -tool bases, engine blocks, cylinder heads, pump housing etc, Flin (1963), Bobojama and Asuquo (1985). Sand is an important casting material in the foundry processes also when combined with other materials such as binder, additives etc, it has an extra ordinary combination of properties for industrial application. The advantages of sand casting include the fact that any metal can be cast irrespective of sizes, shapes or weights. However the disadvantages include poor surface finishing and requirement of wide tolerance. Casting methods usually depends on the type of metal to be cast. Plaster moulds and die moulds are limited to nonferrous metals. In the die casting the liquid metal is forced into a mould at a relatively high pouring rate and allowed to solidify. Permanent mould casting has inherent advantages: Rapid casting rates are possible making this an inexpensive method and furthermore, a single set of dies may be used for several casting. Some of the properties required of a good casting include: permeability, refractoriness, plasticity or flowability, collapsibility, fineness, cohesiveness, chemical receptivity etc. Under normal condition, like all metallurgical products, casting of aluminium contains certain imperfection, which contributes to normal quality variation. Such imperfections are taken as defects or flaws only when they affect the appearance or the satisfactory functioning of the casting and the castings in turn do not measure up to the quality and inspection standard being applied. Donald and Askeland(1990), Higgins (1988), Honeycombe and Hancock (1989), Williams (1990). The aim of this work is to study the effect of changes in mechanical properties of aluminium alloy cooled under different media.

\section{MATERIALS AND METHODS}

Aluminium scraps were obtained from Nigeria Aluminium Extrusion Company limited (Nigalex)
Oshodi, Lagos. Two moulding processes namely permanent die casting and green sand casting moulds were used to produce the cast samples (diameter $12 \mathrm{~mm}$ by $100 \mathrm{~mm}$ long) from which test specimens were obtained. The sample from sand moulds were made using wood patterns with adequate shrinkage allowances and prepared by mixing silica sand with bentonite to improve its bonding strength. Melting was carried out in a crucible furnace. After melting, the molten metal was poured into the mold and the casting was allowed to solidify before shakeout. For the permanent mould process, a two-piece permanent steel mould or die was employed. When clamped together, the two pieces form the desired shape of the cast sample. The molten metal was poured and when complete solidification had been achieved, the die pieces were opened and the cast piece ejected. For the permanent die casting, four metal mould dies were prepared (labeled A, C, D, and E) and were preheated before casting. The sand mould was labeled as sample B. To obtain castings with different structures and mechanical properties, each of the permanent die moulds were placed in different cooling media during casting as follows:

- The first die mould labeled A was cooled in open air after pouring.

- The second mould which was the green sand mould was labeled Sample B.

- $\quad$ The third die mould labeled $\mathrm{C}$ was placed in a container $3 / 4$ filled with water and after casting was allowed to remain there to cool.

- The fourth die mould (Sample D) was placed in a container filled with wet sand and after casting was allowed to cool there before removal. .

- The fifth die mould was put in dry sand and casting was allowed to cool in the dry sand, (Sample E).

Specimens were prepared from the cast products (by cleaning, machining and grinding) for various tests: prepared for microstructure, hardness and tensile tests. The hardness value of each sample was determined by pressing an indenter at four 
different points on each of the samples labeled A - E surface to obtain average value of the hardness number. Samples for microstructural studies were selected from positions, which give average compositional representative of the specimen. Preparation of metal sample for microexamination was carried out by mounting, grinding, polishing and etching. Grinding operation was done using various grades of emery papers. The final polishing was carried out on a rotating disc polisher until the polished surface of each sample became scratch-free mirror like. It was then taken for etching by applying $25 \%$ Hydrofluoric acid with the aid of cotton wool on selective surface of polished sample, and later rinsed in ethyl alcohol and finally dried. The tensile strength tests were carried out by gripping he samples in the jaws of a tensile testing machine. The sample in the chuck was subjected to tensile stress until it necked and finally fractured. The process was repeated for each sample. The tensile results and graphs obtained were recorded.

\section{RESULTS AND DISCUSSIONS}

Table 1 show the average chemical composition of the cast metal determined spectrometrically. Tables 2 and 3 show the results of the effect of the cooling media on the mechanical properties. The strength-deformation characteristics of the cast samples are presented in Figures 1-4. From
Figure 1, it could be seen that the specimen obtained from the air cooled permanent die casting mould (Sample A) have the highest UTS of $197.59 \mathrm{~N} / \mathrm{mm}^{2}$, and also has the highest yield stress, fracture stress as well as the highest hardness values, Tables 2 and 3 . The strain at fracture for this specimen (sample A) was 0.0417, while the average hardness value was $58.13 \mathrm{HBN}$. Sample B obtained by green sand casting has low yield stress $\left(38.4 \mathrm{~N} / \mathrm{mm}^{2}\right)$ but relatively high UTS $\left(168 \mathrm{~N} / \mathrm{mm}^{2}\right)$ and fracture stress $\left(144 \mathrm{~N} / \mathrm{mm}^{2}\right)$. The average hardness values of sample B $(56.18 \mathrm{HBN})$ was closer to the hardness value of sample A. Figures 3 and 4 show deformation characteristics of samples $\mathrm{C}$ and $\mathrm{D}$ obtained by cooling the permanent die mould using water and wet sand respectively. The results show that both samples exhibit comparatively low strength as indicated by the UTS and fracture stress values. The specimen obtained from cooling the die in dry sand (sample E) could not be mached hence the deformation characteristics were not obtained. The calculated yield ratio (i.e. the ratio of the yield stress to the tensile stress) which is a measure of the degree of plasticity of the material is least in sample B, (0.226) and highest in sample A, (0.422). To enhance the plastic deformability of a metal it is important to hold its yield ratio down to some degrees. Thus it was generally observed that the yield stress, UTS and the fracture stress values

Table 1: The result of chemical composition of the aluminium products

\begin{tabular}{lccccccccccc}
\hline Element & $\mathbf{A l}$ & $\mathbf{M g}$ & $\mathbf{S i}$ & $\mathbf{F e}$ & $\mathbf{C u}$ & $\mathbf{M n}$ & $\mathbf{Z n}$ & $\mathbf{C r}$ & $\mathbf{T i}$ & $\mathbf{C a}$ & $\mathbf{S r}$ \\
\hline$W t \%$ & 98.49 & 0.5106 & 0.4743 & 0.3490 & 0.3210 & 0.0586 & 0.0564 & 0.0157 & 0.0117 & 0.0004 & 0.0001 \\
\hline
\end{tabular}

Table 2: Yield Stress, UTS and Fracture Stress Values for the Cast Samples

\begin{tabular}{lcccc}
\hline \multicolumn{1}{c}{ Sample } & $\begin{array}{c}\text { Yield Stress } \\
\left(\mathbf{N} / \mathbf{m m}^{2}\right)\end{array}$ & $\begin{array}{c}\text { Ultimate Tensile Strength } \\
(\mathbf{U T S})\left(\mathbf{N} / \mathbf{m m}^{2}\right)\end{array}$ & $\begin{array}{c}\text { Fracture Stress } \\
\left(\mathbf{N} / \mathbf{m m}^{2}\right)\end{array}$ & $\begin{array}{c}\text { Yield Ratio (yield } \\
\text { stress/UTS) }\end{array}$ \\
\hline Air Cooled Die (A) & 83.20 & 197.59 & 184.59 & 0.4220 \\
Sand Casting (B) & 38.40 & 168.00 & 144.00 & 0.2260 \\
Die with outer water cooled (C) & 38.30 & 151.20 & 124.80 & 0.2540 \\
Die in dry sand (D) & 19.98 & 49.94 & 39.95 & 0.400 \\
Die in wet sand (E) & - & - & - & - \\
& & & & \\
\hline
\end{tabular}


Table 3: Hardness Test Results (HBN)

\begin{tabular}{cccccc}
\hline Trials & Sample A & Sample B & Sample C & Sample D & Sample E \\
\hline i & 57.30 & 55.50 & 46.50 & 44.50 & 43.50 \\
ii & 58.00 & 56.00 & 48.00 & 45.50 & 43.00 \\
iii & 58.70 & 56.50 & 47.50 & 45.00 & 42.50 \\
iv & 58.50 & 56.70 & 46.70 & 45.50 & 43.70 \\
Average & 58.13 & 56.18 & 47.15 & 45.13 & 43.18 \\
\hline
\end{tabular}
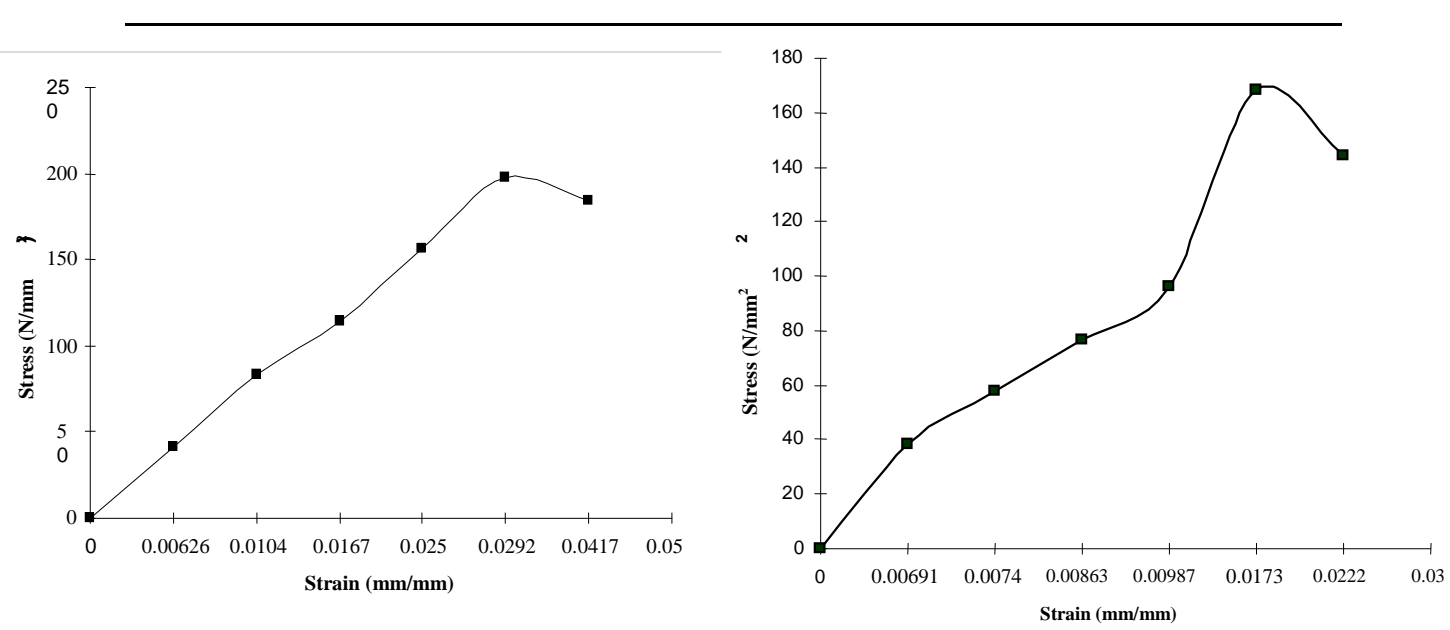

Fig 1: Variation of Stress with Strain for air Cooled Die Cast (Sample A)

Fig. 2: Variations of Stress with Strain for Green Sand Cast (Sample B)
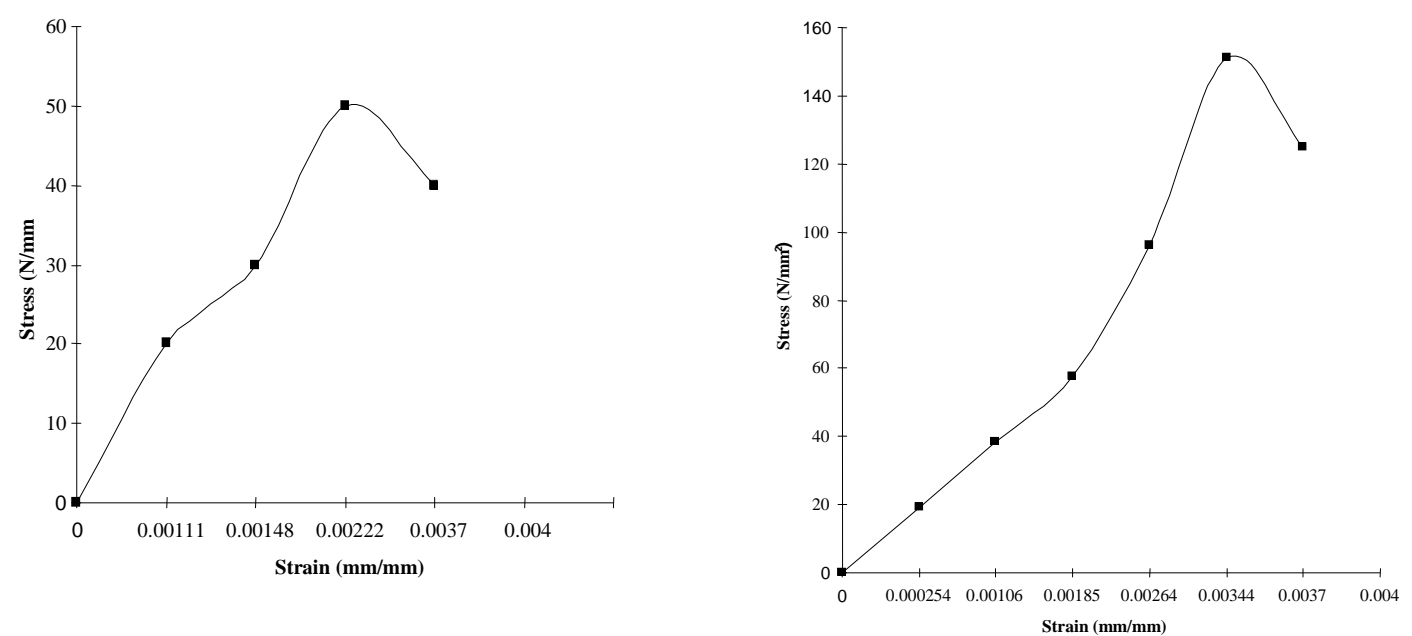

Fig. 3: Variation of Stress with Strain for Water Cooled Die Cast (Sample C

Fig. 4: Variation of Stress with Strain for Wet Sand Cooled Die Cast (Sample D) 
varies with the rate of cooling of the Aluminium alloy cast. The samples obtained from the air cooled die are harder than the green sand casting specimens. Sample C with low yield stress and high tensile strength is soft and the yield ratio is also low (0.254). Sample D with low tensile values is found to be softer but the yield ratio of this sample (0.4) is higher than the sand casting samples. Plates 1-5 show the micrographs of the various specimens obtained.

All the specimens subjected to tensile tests were found to elongate proportionally to load up to the

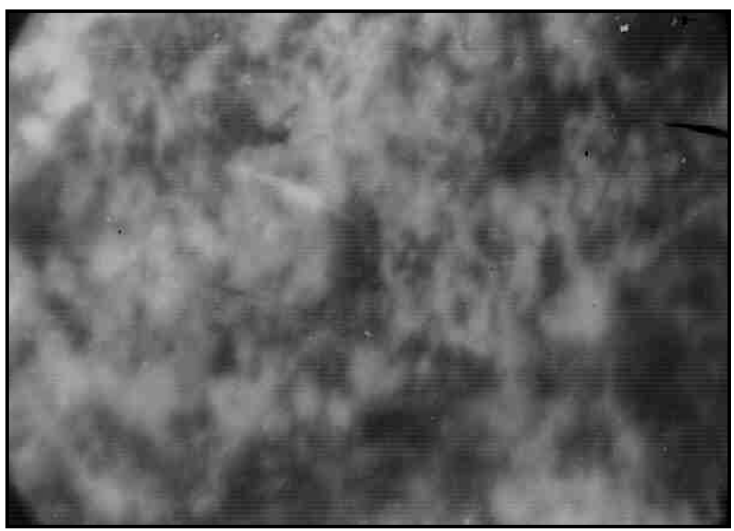

Plate 1: Air Cooled Die Cast (Sample A)x100

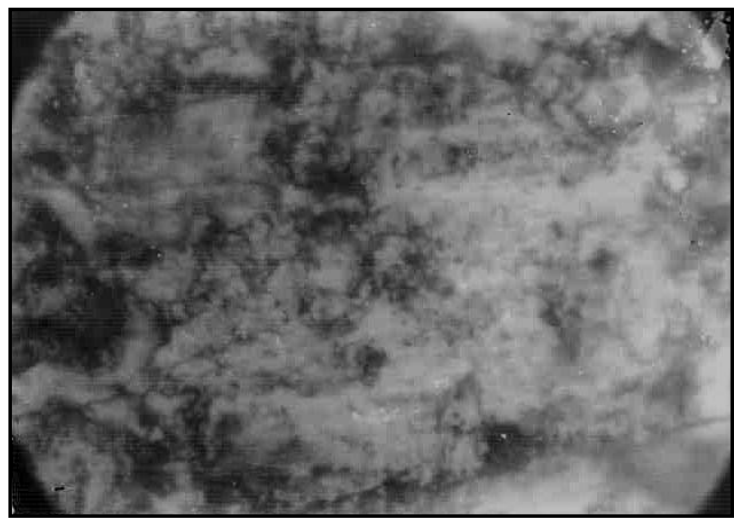

Plate 3: Water Cooled Die Cast (Sample C) x100 proportional limit, i.e. the range of elastic limit behaviour and continue to deform elastically although not strictly linearly up to the yield points. With increasing load, the specimens begin to yield or rather begin to undergo plastic deformation (permanent deformation), hence the relationship between the stress and strain in the diagrams are no longer linear. Failures only occurred in all the materials after extensive deformation, with sampleA having the highest stress at fracture and sample D having the least value. It is generally known that every material has a differently shaped stress - strain curve and the shapes of the stress strain

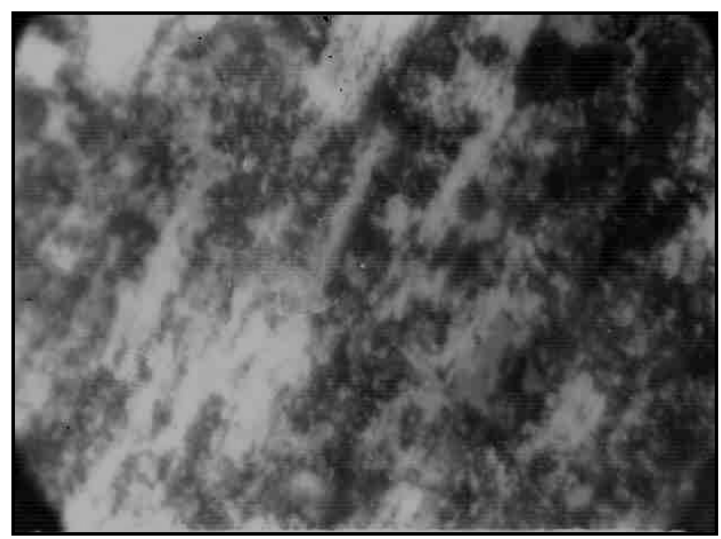

Plate 2: Green Sand Cast (Sample B)x100

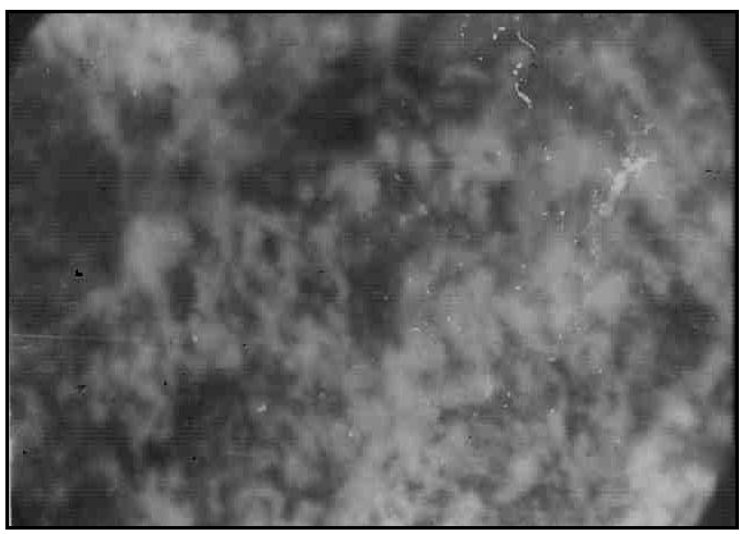

Plate 4: Wet Sand Cooled Die Cast (Sample D) x100 


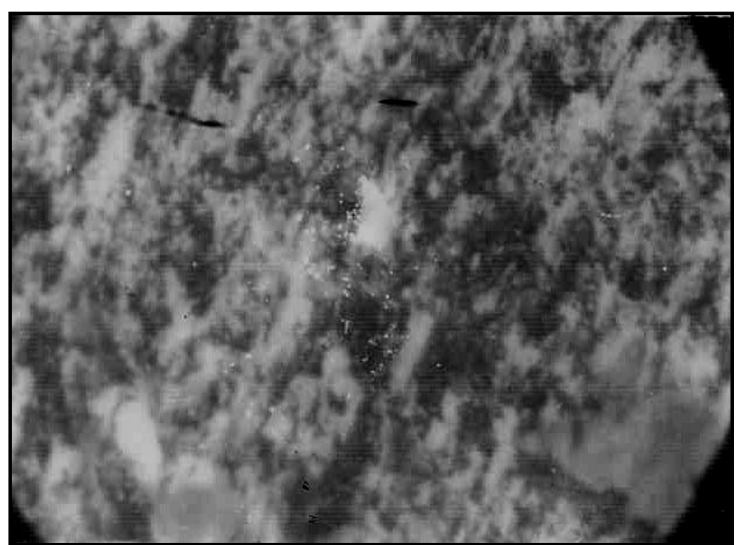

Plate 5: Dry Sand Cooled Die Cast (Sample E) x100

curves generally depend on the composition and structure of the material. This assertion is confirmed by the stress strain curve obtained for each specimen. It was generally observed that the higher the yield stress, the higher the UTS and the higher the fracture stress.

\section{CONCLUSION}

From the research undertaken, the following conclusions were drawn: The rate of cooling contributed positively or otherwise to the mechanical properties of cast aluminium depending on the desired properties. The following hardness results were obtained, $58.13 \mathrm{HBn}, 56.18 \mathrm{HBn}, 47.15 \mathrm{HBn}$, $45.13 \mathrm{HBn}$ and $43.18 \mathrm{HBn}$ for Sample A, Sample B, Sample C, Sample D and Sample E respectively. Samples B and C with low yield ratio has enhanced plastic deformability. Variation in insulating property of the cooling media affects the surface finish, the fineness, the strength and hard- ness which are parts of engineering requirements for material characterization and selection.

\section{ACKNOWLEDGEMENT}

The technical assistance of Olanrewaju S.O. and Rotibi O.M is highly appreciated.

\section{REFERENCES}

Adewuyi. B.O, (2001), Effect of Cooling Rate on Microstructure and Mechanical Properties of a Cast Aluminum Alloy. Journal Of Science and Engineering Technology, 2 (2); 2930 2937.

Bobo-Jama, L. and Asuquo, L. (1985): Foundry Technology First Edition, Abil Publisher, Enugu and Lagos, Nigeria Pp. 9-50.

Donald, R. and Askeland, Y. (1990): Science and Engineering of Materials. Second Edition. Publisher Chapman and Hall London. Pp.92 95.

Flinn, R. A. (1963): Fundamentals of Metal Casting, Addison Wesley. Pp. $162-170$.

Higgins, R.A. (1988): Engineering Metallurgy. Part II Fifth Edition, Suffolk and Haftnolls Limited, Cornwell, England. Pp. . 30-45; 7389.

Honeycombe, R. W. K. and Hancock, P. (1989): Metallurgy of the Light Metals. $2^{\text {nd }}$ Edition

William F. S. (1990): Principles of Materials Science and Engineering, Second edition McGraw - Hill Inc. London 